\title{
Regulation of Intestinal Cholesterol Absorption: A Disease Perspective
}

\author{
Jahangir Iqbal*, Ali Al Qarni, Abbas Hawwari \\ King Abdulaziz Medical City Hospital, Al Ahsa, KAIMRC, MNGHA, Saudi Arabia \\ Email: ^iqbalja@ngha.med.sa
}

How to cite this paper: Iqbal, J., Al Qarni, A. and Hawwari, A. (2017) Regulation of Intestinal Cholesterol Absorption: A Disease Perspective. Advances in Biological Chemistry, 7, 60-75. https://doi.org/10.4236/abc.2017.71004

Received: December 20, 2016

Accepted: February 21, 2017

Published: February 24, 2017

Copyright $\odot 2017$ by authors and Scientific Research Publishing Inc. This work is licensed under the Creative Commons Attribution International License (CC BY 4.0).

http://creativecommons.org/licenses/by/4.0/ (c) (i) Open Access

\begin{abstract}
Hypercholesterolemia promotes atherosclerosis and precise regulation of cholesterol homeostasis is essential. Besides risk factor for cardiovascular disease, abnormalities in cholesterol metabolism have been associated with type 2 diabetes. Cholesterol homeostasis in the body is maintained by de novo synthesis. Furthermore, intestinal cholesterol absorption has recently been considered as an important control point in cholesterol homeostasis. Important insights have been gained into the mechanisms of transport of cholesterol from the intestinal lumen into the enterocytes. Several transporter proteins that appear to be key players in the control of the cholesterol absorption from the intestinal lumen have been identified. Here, we review intestinal cholesterol absorption and the mechanisms underlying alterations in cholesterol absorption under physiological conditions and in diseases such as diabetes mellitus.
\end{abstract}

\section{Keywords}

Cholesterol Absorption, Atherosclerosis, Metabolic Disease, NPC1L1, ATP-Binding Cassette Transporters

\section{Introduction}

Cholesterol and its metabolites such as bile salts, steroid hormones and oxysterols fulfill important biological functions [1]. Cholesterol serves as vital component for vertebrate cell membrane structure and function [2]. Cholesterol in the body is produced in the liver and peripheral tissues, representing an endogenous pool, and absorbed from the intestine, representing dietary or biliary sources [3]. The liver is a major organ for the syntheses and secretion of endogenous cholesterol [4] and secretes $\sim 1 \mathrm{~g}$ of daily cholesterol. Intestine absorbs approximately $50 \%$ of the cholesterol which represents $\sim 400 \mathrm{mg}$ of dietary cholesterol daily [5] [6]; the remainder is excreted in feces [7] [8]. 
Plasma cholesterol level depends on many dietary and genetic factors and is influenced by intestinal cholesterol absorption and hepatic cholesterol synthesis. Precise regulation of cholesterol homeostasis is essential, and it is well known that hypercholesterolemia promotes atherosclerosis and thereby represents a major risk factor for cardiovascular disease [9] [10] [11]. Besides risk factor for cardiovascular disease, abnormalities in cholesterol metabolism have been associated with type 2 diabetes. In several cross-sectional studies, insulin resistance and obesity have been found to be associated with enhanced cholesterol synthesis and reduced cholesterol absorption [12] [13] [14] [15] [16]. Diabetic dyslipidemia is typically characterized by increased very low density lipoprotein (VLDL) and reduced high density lipoprotein (HDL), but surprisingly no change in low-density lipoprotein (LDL) cholesterol levels [17].

Cholesterol homeostasis in the body is maintained by de novo synthesis. The liver, which facilitates clearance of VLDL particles and cholesterol-containing chylomicron remnants, has been considered the major site of control in maintenance of cholesterol homeostasis [18]. The biosynthesis of cholesterol involves a variety of enzymatic reactions that are well-defined and feedback-regulated [19]. In recent years, the importance of the intestine which has a major impact on cholesterol homeostasis at the level of cholesterol absorption, fecal excretion and de novo synthesis is increasingly recognized in many aspects of cholesterol physiology [20]. Niemann-Pick C1-Like 1 (NPC1L1), which is a target of dietary cholesterol uptake inhibitor ezetimibe, mediates intestinal cholesterol absorption and biliary cholesterol re-absorption [21]. On the other hand, the heterodimer of ATP-binding cassette (ABC) transporters G5 and G8 (ABCG5/G8) mediates the efflux of cholesterol and plant sterols in the enterocytes from the diet back into the lumen [22]. Expression of these genes is regulated by the peroxisome proliferator-activated receptors (PPARs) [23] and the nuclear liver X receptors (LXRs) [24]. Furthermore, direct secretion of cholesterol from the blood compartment into the intestine, also known as transintestinal cholesterol excretion (TICE), plays a major role in disposal of cholesterol via the feces, at least in mice [25]. An increase in intestinal absorption of cholesterol occurs in diseases such as diabetes mellitus leading to high plasma cholesterol and increased risk of cardiovascular diseases. The metabolic states and biological processes that regulate cholesterol homeostatic pathways in the intestine are poorly understood. This review focuses on recent developments in research related to intestinal cholesterol absorption and discusses recent understandings of the role of different transporter proteins involved in its regulation.

\section{Intestinal Cholesterol Absorption}

Most dietary cholesterol ( $85 \%$ - 90\%) exists in the form of the free sterol, with only $10 \%-15 \%$ existing as esters of cholesterol. Enterocytes absorb only free cholesterol which is minimally soluble in an aqueous environment [26] [27] and must be partitioned into bile salt micelles prior to absorption. Thus, cholesteryl esters must be hydrolyzed by cholesterol esterase to release free cholesterol for 
absorption. Mixed micelles, composed of free cholesterol along with triglycerides, phospholipids, ionized and nonionized fatty acids, monoacylglycerols, and lysophospholipids [28], are transported to the brush border of the enterocyte, where cholesterol is absorbed. Absorption of cholesterol depends on the presence of bile acids in the intestinal lumen [29] and correlates directly with the total bile acid pool [30].

Before its interaction with transporter proteins responsible for uptake and subsequent transport across the cellular brush border, cholesterol must pass through a diffusion barrier at the intestinal lumen-enterocyte membrane interface. The transfer of cholesterol across the unstirred water layer is facilitated by bile salt micelles. Cholesterol is taken up by the enterocyte with relatively high efficiency compared with structurally similar phytosterols [31] and had long been considered an energy-independent, simple, passive diffusion process. However, discovery of multiple genes [32] [33] [34] that participate in the regulation of cholesterol absorption and several molecules that appear to inhibit it [35] strongly suggests that a transporter facilitated mechanism is involved. This notion is also supported by interstrain and interindividual variations in the efficiency of intestinal cholesterol absorption [36].

Several proteins have been investigated for their potential roles as intestinal cholesterol transporters using genetically modified animal models. Through these studies, investigators have gained important insights into the mechanisms of transport and identified several transporter proteins that appear to be key players in the control of the cholesterol absorption from the intestinal lumen such as NPC1L1 [32] and the ATP-binding cassette proteins ABCG5 and ABCG8 [33] [34]. The first step in cholesterol absorption in the intestine appears to be through NPC1L1, a glycosylated protein localized at the brush-border membrane of the enterocyte [37] and highly expressed in the jejunum [21]. The identification of NPC1L1 as a putative cholesterol transporter [32] was facilitated by the discovery of ezetimibe [32] [35], a cholesterol absorption inhibitor which reduces diet-induced hypercholesterolemia [38]. NPC1L1 acts as a unidirectional transporter of cholesterol and non-cholesterol sterols [39]. Cholesterol has been shown to bind to the N-terminal domain of NPC1L1 [40]. The deletion of $\mathrm{Npcl} / 1$ in mice results in a reduction in fractional cholesterol absorption [32] (i.e., the percentage of cholesterol absorbed from the intestine, which is determined using a dual-isotope feeding technique). Various mechanisms have been suggested to impair NPC1L1 cholesterol uptake in twenty rare NCP1L1 alleles found in the low cholesterol absorbers [41].

Once cholesterol has been taken up by the enterocytes through NPC1L1, it may be excreted back into the intestinal lumen rather than being further processed for absorption into the lymphatic circulation. ABCG5 and ABCG8, mostly confined to the human small intestine and liver [33], function as a heterodimer and are critical for the control of cholesterol, and in particular non-cholesterol sterols, absorption. Rare mutations in the genes encoding human ABCG5 and ABCG8 transporters result in high levels of plant sterols in 
blood and other tissues. This condition, known as $\beta$-sitosterolemia [33] [34], is caused as a result of enhanced absorption of sterols from the intestines and decreased removal in bile, and manifests itself in children as tendon xanthomas or in young adults as severe coronary heart disease [42]. $A b c g 5$ and $A b c g 8$ deficiency in mice has minimal effect on the efficiency of cholesterol absorption [43] [44] but results in reduced biliary cholesterol secretion [43] and enhanced phytosterol absorption [43] [44]. However, the pharmacological induction or overexpression of $A b c g 5 / g 8$ in mice [45] [46] results in a reduction in fractional cholesterol absorption.

Recent data have strongly suggested that ABCA1 plays a role in the control of cholesterol absorption. ABCA1, which was initially thought to be localized to the apical membrane [47], has also been shown to be present in the basolateral membrane [48]. Studies in Caco-2 cells and in the apoA1 knockout mice showed that basolateral efflux of free cholesterol occurs in high-density apoB-free/ apoA-I containing lipoproteins [49] [50]. Deletion of intestinal $A b c a 1$ resulted in a $30 \%$ decrease in plasma HDL cholesterol levels suggesting a role of ABCA1 in the biogenesis of HDL in the intestine [51]. Furthermore, enterocytes deficient in ABCA1 absorb smaller amounts of cholesterol suggesting its role not only in HDL biogenesis but also in cholesterol absorption [51].

Recent studies have suggested that intestine plays a role in the removal of excess cholesterol from the peripheral tissues to the feces by direct non-biliary excretion of plasma-derived cholesterol into the intestinal lumen [25] [52]. Flux of cholesterol from circulating lipoproteins through the intestine and into the lumen for subsequent excretion or reabsorption is known as transintestinal cholesterol excretion (TICE) [52]. Studies have indicated that fecal sterol loss does not absolutely require biliary cholesterol secretion, and other pathways such as TICE can adequately compensate for biliary insufficiency to maintain normal fecal cholesterol loss [53] [54]. Although TICE can occur throughout the small intestine, but most of the TICE happens in the proximal intestine [55]. Around $20 \%-33 \%$ of basal fecal sterol loss has been estimated due to TICE in both human [56] and mice [57]. It has been shown that the non-biliary TICE pathway can be stimulated by activation of LXR [57] and PPAR $\delta$ [58], ezetimibe administration [59], and fasting [60]. However, the precise underlying mechanisms and pathways for the induction of TICE are still unknown.

Fatty acid translocase CD36 has also been implicated as the cholesterol transporter in brush-border membranes. Overexpression of CD36 in COS-7 cells has been shown to enhance cholesterol uptake from micellar substrates [61]. Furthermore, significant reduction in cholesterol transport from the intestinal lumen to the lymphatic system was observed in CD36-null mice [62]. Observation that intestine-specific overexpression of scavenger receptor class B type I (SR-BI) in mice leads to an increase in cholesterol absorption in short-term absorption experiments [63] suggest that SR-BI play a role in the control of cholesterol absorption. Besides, brush-border membrane vesicles prepared from the proximal intestine of SR-BI knockout mice [61] and Caco-2 cells pre-incubated with anti- 
bodies to SR-BI [64] showed decreased cholesterol uptake. Targeted disruption of SR-BI in mice, however, has little effect on in vivo cholesterol absorption [65], suggesting that SR-BI might not be essential for absorption of cholesterol from the intestine.

\section{Regulation of Intestinal Cholesterol Absorption and Synthesis}

The intestine plays an important role in the tight control of whole-body cholesterol homeostasis. Reducing the expression of NPC1L1 at the level of transcription may reduce cholesterol absorption. In response to cholesterol intake, enterocytes regulate cholesterol absorption by modulating the activity of NPC1L1 through a sterol sensing domain and a sterol regulatory element in the promoter. The PPAR regulates expression of $N p c 1 / 1$ [66]. Fenofibrate, a PPARa agonist, inhibits cholesterol absorption through the transcriptional regulation of NPC1L1 by binding to a response element upstream of the human NPC1 $L 1$ gene [67]. GW610742, a synthetic PPAR $\delta / \beta$ agonist, reduces cholesterol absorption by decreasing $N p c 1 / 1$ expression without altering the expression of $A b c g 5$ and $A b c g 8$ [66]. A cholesterol-rich diet suppresses the expression of $N p c 1 / 1$ in mice, whereas its expression is enhanced in the cholesterol-depleted porcine intestine [68]. Upon cholesterol deprivation, NPC1L1, present mostly in intracellular membranes, is translocated to the plasma membrane where it can pick up cholesterol and transport it to the ER for esterification and packaging into nascent lipoproteins [69]. The efficiency of cholesterol absorption is higher in type 2 diabetic subjects with coronary artery disease compared to those without this disease [70]. NPC1L1 mRNA expression is elevated in patients with type 2 diabetes [71]. Furthermore, these patients also have reduced expression of the cholesterol efflux transporters ABCG5 and ABCG8, suggesting that cholesterol absorption is higher.

The LXRs and their target genes regulate pathways involved in the metabolism of cholesterol [24]. To activate gene transcription, these receptors form a heterodimer with the retinoid $\mathrm{X}$ receptor after activation by their natural ligands (e.g., oxysterols) [72] that bind to specific LXR response elements in the promoter regions of their target genes. LXRs control cholesterol efflux by regulating expression of $\mathrm{ABCA} 1$ and $\mathrm{ABCG} 1$ [73] and its upregulation results in increased transfer of intracellular cholesterol to HDL particles [74]. Activation of LXRs also regulates expression of ABCG5 and ABCG8 [75] and promote the efflux of cholesterol to limit cholesterol absorption.

Besides regulation of cholesterol absorption by PPARs and LXRs, esterification of intracellular cholesterol by two ER membrane-localized enzymes, acylCoA:cholesterol acyltransferase 1 (ACAT1) and ACAT2, has also been shown to regulate absorption of cholesterol [76]. Even though ACAT1 is expressed ubiquitously [77], its level of expression in the mouse small intestine is very low [78]. On the other hand, expression of ACAT2 is very high in the small intestine and liver [79] [80]. ACAT2, which is specific for cholesterol but not plant sterols, 
is the predominant enzyme responsible for the synthesis and secretion of cholesterol esters with lipoproteins. The rate of cholesterol absorption is significantly reduced in ACAT2 deficient mice [81]. Substrate availability significantly enhances the rate of cholesterol esterification of these enzymes and it is inhibited by product accumulation which is relieved by microsomal triglyceride transfer protein (MTP) [82]. MTP transfers cholesterol esters from the ER membranes to nascent apoB-lipoproteins and its importance in cholesterol absorption has been well documented [83]. Reesterification of absorbed cholesterol within the enterocytes is important for bulk entry of cholesterol into nascent chylomicrons. It is an important regulator of cholesterol absorption from the intestine that enhances the diffusion gradient to favor the entry of intraluminal cholesterol into the cell. Thus, the rate of cholesterol absorption is significantly reduced by deletion of Acat2 [81] or pharmacological inhibition of ACAT [84].

After liver, intestine is an important organ for cholesterol synthesis and makes up $25 \%$ of de novo cholesterol synthesis. Cholesterol is synthesized in the endoplasmic reticulum (ER) by the concerted action of several enzymes in the mevalonate pathway. Cholesterol synthesis is regulated by the rate limiting enzyme in the synthetic pathway called 3-hydroxy-3-methylglutaryl co-enzyme A (HMG-CoA) reductase which converts HMG-CoA into mevalonate. This enzyme is tightly regulated at both transcriptional and post-translational levels and is the pharmacological target for cholesterol lowering drugs such as statins. Inhibition of HMG-CoA reductase has been shown to increase cholesterol absorption through a lowering of ABCG5/G8 and an increase in NPC1L1 [85]. Studies have suggested that the intestine may play an important role in the diabetesinduced increase in plasma cholesterol levels. In streptozocin-induced diabetic rats, de novo cholesterol synthesis in the intestine, and not in the liver, is increased two- to three-fold [86]. Similar results of increased cholesterol synthesis in the intestine have been observed in different diabetic animal models [87]. Activity of HMG-CoA reductase increases in the intestine of diabetic rats [88]. However, in the liver, HMG-CoA reductase activity is normal in moderately diabetic rats [89]. These observations suggest that an enhancement of intestinal cholesterol synthesis may be a general phenomenon in diabetic animals.

\section{Pharmacological Targeting of Intestinal Cholesterol Absorption}

Cholesterol is an important biological component of cell membranes, and plays an important role in several biosynthetic pathways such as steroid hormone and bile acid synthesis. However, high levels of cholesterol are associated with increased atherosclerosis. Besides risk factor for cardiovascular disease, abnormalities in cholesterol metabolism have been associated with type 2 diabetes. Therefore, maintenance of cholesterol homeostasis is critical for preventing such diseases. Intestine has been shown to play an important role to maintain its homeostasis [20] and has emerged as a dynamic organ with tremendous therapeutic potential for lowering cholesterol. 
In a substantial proportion of individuals, statin therapy is not sufficient to prevent the risk of cardiovascular disease [90]. Therefore, a particular interest has been shown to understand the processes that govern the transcellular movement of cholesterol across the absorptive cells of the intestinal tract for developing new drugs for the treatment of coronary artery disease. Ezetimibe has been shown to specifically decrease cholesterol absorption after binding to NPC1L1 [91]. Furthermore, ezetimibe has been shown to inhibit the development and progression of atherosclerosis in ApoE knockout mice by reducing cholesterol absorption and plasma cholesterol levels [92]. Similarly, a significant reduction in cholesterol absorption and significant protection from the development of atherosclerosis was observed in NPC1L1 and ApoE double knockout mice [93]. In humans, ezetimibe monotherapy or combined treatment with statins has been very effective to decrease hypercholesterolemia [94] [95].

Cholesterol absorption has been shown to be increased in both animal and human diabetes [96] due to an increase in NPC1L1. Ezetimibe treatment or NPC1L1 deficiency has been shown to improve many metabolic disorders besides hypercholesterolemia in rodents. Hepatic steatosis and insulin sensitivity was improved in leptin receptor deficient Zucker obese rats treated with ezetimibe [97] [98]. Furthermore, ezetimibe treatment or NPC1L1 deficiency was shown to attenuate insulin resistance in mice fed a high fat diet [99] suggesting that inhibition of cholesterol absorption through NPC1L1 could be a potential therapeutic approach to treat metabolic diseases.

Rats with induced diabetes have been shown to have impaired expression of ABCG5/G8 that was partially reversed with insulin treatment [100]. Similarly, this trend in impairment was found in Zucker diabetic rats [101] and in type 2 diabetic subjects [71]. Plant sterols and stanols have been effectively shown to lower plasma cholesterol levels in familial hypercholesterolemia patients through ABCG5/G8 transporters [102]. Use of these sterols and stanols as cholesterollowering agents and as biomarkers of cardiovascular disease have been reviewed [103] [104]. Although ezetimibe and plant sterols reduced plasma cholesterol to a similar extent, however, a greater protective effect was shown by ezetimibe on atherosclerotic lesion area [105]. Some studies have raised concerns over the use of plant sterols that accumulate in vascular lesions with increasing supplementation [106]. Therefore, use of plant sterols as a therapeutic intervention needs further evaluation.

\section{Summary}

The intestine is an attractive target for reducing cardiovascular risk because it contains several transporters that regulate cholesterol absorption. Cholesterol absorption from intestinal lumen into enterocytes and secretion to plasma circulation is a complex process. Several transporters on the apical surface of brush-border membranes regulate the amount of cholesterol taken up by the enterocytes. An essential role for NPC1L1 in cholesterol absorption is well established. Once absorbed, cholesterol is either effluxed back into the lumen by 
coordinated activity of the two ABC half transporters, ABCG5 and ABCG8, or transported from the plasma membrane to intracellular compartments where it can be packaged into lipoproteins, or secreted directly on the basolateral side by ABCA1. Identification NPC1L1 as a cholesterol transporter on apical brushborder membranes have been fruitful for the improvement of treatment strategies to suppress cholesterol absorption in reducing hypercholesterolemia and lowering the risk of cardiovascular disease. Recently, NPC1L1 has been the focus of research beyond cholesterol absorption and atherosclerosis and its inhibition has shown beneficial effects in animals on many components of the metabolic syndrome. Further studies need to be done to find better approaches to decrease metabolic diseases by regulating intestinal cholesterol absorption.

\section{Competing Interests}

The authors declare that they have no competing interests.

\section{Authors' Contributions}

JI participated in collection of literature, manuscript preparation and final drafting. AAQ and AH contributed with critical assessment on the subject based on published work in the area.

\section{References}

[1] Rezen, T., Rozman, D., Pascussi, J.M. and Monostory, K. (2011) Interplay between Cholesterol and Drug Metabolism. Biochimica et Biophysica Acta, 1814, 146-160. https://doi.org/10.1016/j.bbapap.2010.05.014

[2] Maxfield, F.R. and Tabas, I. (2005) Role of Cholesterol and Lipid Organization in Disease. Nature, 438, 612-621. https://doi.org/10.1038/nature04399

[3] Iqbal, J. and Hussain, M.M. (2009) Intestinal Lipid Absorption. American Journal of Physiology, Endocrinology and Metabolism, 296, E1183-E1194. https://doi.org/10.1152/ajpendo.90899.2008

[4] Van der Wulp, M.Y., Verkade, H.J. and Groen, A.K. (2013) Regulation of Cholesterol Homeostasis. Molecular and Cellular Endocrinology, 368, 1-16. https://doi.org/10.1016/j.mce.2012.06.007

[5] Grundy, S.M. and Metzger, A.L. (1972) A Physiological Method for Estimation of Hepatic Secretion of Biliary Lipids in Man. Gastroenterology, 62, 1200-1217.

[6] Wilson, M.D. and Rudel, L.L. (1994) Review of Cholesterol Absorption with Emphasis on Dietary and Biliary Cholesterol. Journal of Lipid Research, 35, 943-955.

[7] Bays, H. (2002) Ezetimibe. Expert Opinion on Investigational Drugs, 11, 1587-1604. https://doi.org/10.1517/13543784.11.11.1587

[8] Clearfield, M.B. (2003) A Novel Therapeutic Approach to Dyslipidemia. Journal of the American Osteopathic Association, 103, S16-S20.

[9] Kannel, W.B., Castelli, W.P. and Gordon, T. (1979) Cholesterol in the Prediction of Atherosclerotic Disease. New Perspectives Based on the Framingham Study. Annals of Internal Medicine, 90, 85-91. https://doi.org/10.7326/0003-4819-90-1-85

[10] Liu, J., Sempos, C.T., Donahue, R.P., Dorn, J., Trevisan, M. and Grundy, S.M. (2006) Non-High-Density Lipoprotein and Very-Low-Density Lipoprotein Cholesterol and Their Risk Predictive Values in Coronary Heart Disease. American Jour- 
nal of Cardiology, 98, 1363-1368. https://doi.org/10.1016/j.amjcard.2006.06.032

[11] Steinberg, D. (1989) The Cholesterol Controversy Is Over. Why Did It Take So Long? Circulation, 80, 1070-1078. https://doi.org/10.1161/01.CIR.80.4.1070

[12] Simonen, P.P., Gylling, H.K. and Miettinen, T.A. (2002) Diabetes Contributes to Cholesterol Metabolism Regardless of Obesity. Diabetes Care, 25, 1511-1515. https://doi.org/10.2337/diacare.25.9.1511

[13] Simonen, P., Gylling, H. and Miettinen, T.A. (2008) The Validity of Serum Squalene and Non-Cholesterol Sterols as Surrogate Markers of Cholesterol Synthesis and Absorption in Type 2 Diabetes. Atherosclerosis, 197, 883-888.

https://doi.org/10.1016/j.atherosclerosis.2007.08.003

[14] Pihlajamaki, J., Gylling, H., Miettinen, T.A. and Laakso, M. (2004) Insulin Resistance Is Associated with Increased Cholesterol Synthesis and Decreased Cholesterol Absorption in Normoglycemic Men. Journal of Lipid Research, 45, 507-512. https://doi.org/10.1194/jlr.M300368-JLR200

[15] Miettinen, T.A. and Gylling, H. (2000) Cholesterol Absorption Efficiency and Sterol Metabolism in Obesity. Atherosclerosis, 153, 241-248. https://doi.org/10.1016/S0021-9150(00)00404-4

[16] Gylling, H., Hallikainen, M., Pihlajamaki, J., Simonen, P., Kuusisto, J., Laakso, M. and Miettinen, T.A. (2010) Insulin Sensitivity Regulates Cholesterol Metabolism to a Greater Extent than Obesity: Lessons from the METSIM STUDY. Journal of Lipid Research, 51, 2422-2427. https://doi.org/10.1194/jlr.P006619

[17] Krauss, R.M. (2004) Lipids and Lipoproteins in Patients with Type 2 Diabetes. Diabetes Care, 27, 1496-1504. https://doi.org/10.2337/diacare.27.6.1496

[18] Dietschy, J.M., Turley, S.D. and Spady, D.K. (1993) Role of Liver in the Maintenance of Cholesterol and Low Density Lipoprotein Homeostasis in Different Animal Species, Including Humans. Journal of Lipid Research, 34, 1637-1659.

[19] Robichon, C. and Dugail, I. (2007) De Novo Cholesterol Synthesis at the Crossroads of Adaptive Response to Extracellular Stress through SREBP. Biochimie, 89, 260-264. https://doi.org/10.1016/j.biochi.2006.09.015

[20] Kruit, J.K., Groen, A.K., Van Berkel, T.J. and Kuipers, F. (2006) Emerging Roles of the Intestine in Control of Cholesterol Metabolism. World Journal of Gastroenterology, 12, 6429-6439. https://doi.org/10.3748/wjg.v12.i40.6429

[21] Wang, L.J. and Song, B.L. (2012) Niemann-Pick C1-Like 1 and Cholesterol Uptake. Biochimica et Biophysica Acta, 1821, 964-972. https://doi.org/10.1016/j.bbalip.2012.03.004

[22] Brown, J.M. and Yu, L. (2009) Opposing Gatekeepers of Apical Sterol Transport: Niemann-Pick C1-Like 1 (NPC1L1) and ATP-Binding Cassette Transporters G5 and G8 (ABCG5/ABCG8). Immunology Endocrine and Metabolic Agents in Medicinal Chemistry, 9, 18-29. https://doi.org/10.2174/187152209788009797

[23] Degirolamo, C., Sabba, C. and Moschetta, A. (2015) Intestinal Nuclear Receptors in HDL Cholesterol Metabolism. JOurnal of Lipid Research, 56, 1262-1270. https://doi.org/10.1194/jlr.R052704

[24] Bonamassa, B. and Moschetta, A. (2013) Atherosclerosis: Lessons from LXR and the Intestine. Trends in Endocrinology and Metabolism, 24, 120-128. https://doi.org/10.1016/j.tem.2012.10.004

[25] Van der Velde, A.E., Brufau, G. and Groen, A.K. (2010) Transintestinal Cholesterol Efflux. Current Opinion in Lipidology, 21, 167-171. https://doi.org/10.1097/MOL.0b013e3283395e45

[26] Holt, P.R., Fairchild, B.M. and Weiss, J. (1986) A Liquid Crystalline Phase in Hu- 
man Intestinal Contents during Fat Digestion. Lipids, 21, 444-446. https://doi.org/10.1007/BF02536401

[27] Swell, L., Trout, E.C., Hopper, J.R., Field, H. and Treadwell, C.R. (1958) Specific Function of Bile Salts in Cholesterol Absorption. Proceedings of the Society for EXperimental Biology and Medicine, 98, 174-176. https://doi.org/10.3181/00379727-98-23979

[28] Yao, L., Heubi, J.E., Buckley, D.D., Fierra, H., Setchell, K.D., Granholm, N.A., Tso, P., Hui, D.Y. and Woollett, L.A. (2002) Separation of Micelles and Vesicles within Lumenal Aspirates from Healthy Humans: Solubilization of Cholesterol After a Meal. Journal of Lipid Research. 43, 654-660.

[29] Voshol, P.J., Schwarz, M., Rigotti, A., Krieger, M., Groen, A.K. and Kuipers, F. (2001) Down-Regulation of Intestinal Scavenger Receptor Class B, Type I (SR-BI) Expression in Rodents under Conditions of Deficient Bile Delivery to the Intestine. Biochemical Journal, 356, 317-325. https://doi.org/10.1042/bj3560317

[30] Ponz de, L.M., Loria, P., Iori, R. and Carulli, N. (1981) Cholesterol Absorption in Cirrhosis: The Role of Total and Individual Bile Acid Pool Size. Gastroenterology, 80, 1428-1437.

[31] Moreau, R.A., Whitaker, B.D. and Hicks, K.B. (2002) Phytosterols, Phytostanols, and Their Conjugates in Foods: Structural Diversity, Quantitative Analysis, and Health-Promoting Uses. Progress in Lipid Research, 41, 457-500. https://doi.org/10.1016/S0163-7827(02)00006-1

[32] Altmann, S.W., Davis, H.R., Zhu, L.J., Yao, X., Hoos, L.M., Tetzloff, G., Iyer, S.P., Maguire, M., Golovko, A., Zeng, M., Wang, L., Murgolo, N. and Graziano, M.P. (2004) Niemann-Pick C1 Like 1 Protein Is Critical for Intestinal Cholesterol Absorption. Science, 303, 1201-1204. https://doi.org/10.1126/science.1093131

[33] Berge, K.E., Tian, H., Graf, G.A., Yu, L., Grishin, N.V., Schultz, J., Kwiterovich, P., Shan, B., Barnes, R. and Hobbs, H.H. (2000) Accumulation of Dietary Cholesterol in Sitosterolemia Caused by Mutations in Adjacent ABC Transporters. Science, 290, 1771-1775. https://doi.org/10.1126/science.290.5497.1771

[34] Lu, K., Lee, M.H., Hazard, S., Brooks-Wilson, A., Hidaka, H., Kojima, H., Ose, L., Stalenhoef, A.F., Mietinnen, T., Bjorkhem, I., Bruckert, E., Pandya, A., Brewer, H.B., Salen, G., Dean, M., Srivastava, A. and Patel, S.B. (2001) Two Genes That Map to the STSL Locus Cause Sitosterolemia: Genomic Structure and Spectrum of Mutations Involving Sterolin-1 and Sterolin-2, Encoded by ABCG5 and ABCG8, Respectively. American Journal of Human Genetics, 69, 278-290. https://doi.org/10.1086/321294

[35] Garcia-Calvo, M., Lisnock, J., Bull, H.G., Hawes, B.E., Burnett, D.A., Braun, M.P., Crona, J.H., Davis, H.R., Dean, D.C., Detmers, P.A., Graziano, M.P., Hughes, M., Macintyre, D.E., Ogawa, A., O’Neill, K.A., Iyer, S.P., Shevell, D.E., Smith, M.M., Tang, Y.S., Makarewicz, A.M., Ujjainwalla, F., Altmann, S.W., Chapman, K.T. and Thornberry, N.A. (2005) The Target of Ezetimibe Is Niemann-Pick C1-Like 1 (NPC1L1). Proceedings of the National Academy of Sciences of the United States of America, 102, 8132-8137. https://doi.org/10.1073/pnas.0500269102

[36] Wang, D.Q. (2007) Regulation of Intestinal Cholesterol Absorption. Annual Review of Physiology, 69, 221-248.

https://doi.org/10.1146/annurev.physiol.69.031905.160725

[37] Iyer, S.P., Yao, X., Crona, J.H., Hoos, L.M., Tetzloff, G., Davis, H.R., Graziano, M.P. and Altmann, S.W. (2005) Characterization of the Putative Native and Recombinant Rat Sterol Transporter Niemann-Pick C1 like 1 (NPC1L1) Protein. Biochimica et Biophysica Acta, 1722, 282-292. 
https://doi.org/10.1016/j.bbagen.2004.12.021

[38] Van, H.M., Farley, C., Compton, D.S., Hoos, L.M., Smith-Torhan, A. and Davis, H.R. (2003) Ezetimibe Potently Inhibits Cholesterol Absorption but Does Not Affect Acute Hepatic or Intestinal Cholesterol Synthesis in Rats. British Journal of Pharmacology, 138, 1459-1464. https://doi.org/10.1038/sj.bjp.0705187

[39] Field, F.J., Watt, K. and Mathur, S.N. (2007) Ezetimibe Interferes with Cholesterol Trafficking from the Plasma Membrane to the Endoplasmic Reticulum in $\mathrm{CaCo}_{2}$ Cells. Journal of Lipid Research, 48, 1735-1745. https://doi.org/10.1194/jlr.M700029-JLR200

[40] Zhang, J.H., Ge, L., Qi, W., Zhang, L., Miao, H.H., Li, B.L., Yang, M. and Song, B.L. (2011) The N-Terminal Domain of NPC1L1 Protein Binds Cholesterol and Plays Essential Roles in Cholesterol Uptake. Journal of Biological Chemistry, 286, 25088-25097. https://doi.org/10.1074/jbc.M111.244475

[41] Calandra, S., Tarugi, P., Speedy, H.E., Dean, A.F., Bertolini, S. and Shoulders, C.C. (2011) Mechanisms and Genetic Determinants Regulating Sterol Absorption, Circulating LDL Levels, and Sterol Elimination: Implications for Classification and Disease Risk. Journal of Lipid Research, 52, 1885-1926. https://doi.org/10.1194/jlr.R017855

[42] Lee, M.H., Lu, K., Hazard, S., Yu, H., Shulenin, S., Hidaka, H., Kojima, H., Allikmets, R., Sakuma, N., Pegoraro, R., Srivastava, A.K., Salen, G., Dean, M. and Patel, S.B. (2001) Identification of a Gene, ABCG5, Important in the Regulation of Dietary Cholesterol Absorption. Nature Genetics, 27, 79-83. https://doi.org/10.1038/83799

[43] Yu, L., Hammer, R.E., Li-Hawkins, J., Von, B.K., Lutjohann, D., Cohen, J.C. and Hobbs, H.H. (2002) Disruption of ABCG5 and ABCG8 in Mice Reveals Their Crucial Role in Biliary Cholesterol Secretion. Proceedings of the National Academy of Sciences of the United States of America, 99, 16237-16242. https://doi.org/10.1073/pnas.252582399

[44] Plosch, T., Bloks, V.W., Terasawa, Y., Berdy, S., Siegler, K., Van Der, S.F., Kema, I.P., Groen, A.K., Shan, B., Kuipers, F. and Schwarz, M. (2004) Sitosterolemia in ABC-Transporter G5-Deficient Mice Is Aggravated on Activation of the Liver-X Receptor. Gastroenterology, 126, 290-300. https://doi.org/10.1053/j.gastro.2003.10.074

[45] Yu, L., Li-Hawkins, J., Hammer, R.E., Berge, K.E., Horton, J.D., Cohen, J.C. and Hobbs, H.H. (2002) Overexpression of ABCG5 and ABCG8 Promotes Biliary Cholesterol Secretion and Reduces Fractional Absorption of Dietary Cholesterol. Journal of Clinical Investigation, 110, 671-680. https://doi.org/10.1172/JCI0216001

[46] Yu, L., York, J., Von, B.K., Lutjohann, D., Cohen, J.C. and Hobbs, H.H. (2003) Stimulation of Cholesterol Excretion by the Liver X Receptor Agonist Requires ATP-Binding Cassette Transporters G5 and G8. Journal of Biological Chemistry, 278, 15565-15570. https://doi.org/10.1074/jbc.M301311200

[47] Repa, J.J., Turley, S.D., Lobaccaro, J.A., Medina, J., Li, L., Lustig, K., Shan, B., Heyman, R.A., Dietschy, J.M. and Mangelsdorf, D.J. (2000) Regulation of Absorption and ABC1-Mediated Efflux of Cholesterol by RXR Heterodimers. Science, 289, 1524-1529. https://doi.org/10.1126/science.289.5484.1524

[48] Ohama, T., Hirano, K., Zhang, Z., Aoki, R., Tsujii, K., Nakagawa-Toyama, Y., Tsukamoto, K., Ikegami, C., Matsuyama, A., Ishigami, M., Sakai, N., Hiraoka, H., Ueda, K., Yamashita, S. and Matsuzawa, Y. (2002) Dominant Expression of ATP-Binding Cassette Transporter-1 on Basolateral Surface of $\mathrm{CaCo}_{2}$ Cells Stimulated by LXR/RXR Ligands. Biochemical and Biophysical Research Communications, 296, 
625-630. https://doi.org/10.1016/S0006-291X(02)00853-7

[49] Iqbal, J., Anwar, K. and Hussain, M.M. (2003) Multiple, Independently Regulated Pathways of Cholesterol Transport across the Intestinal Epithelial Cells. Journal of Biological Chemistry, 278, 31610-31620. https://doi.org/10.1074/jbc.M301177200

[50] Iqbal, J. and Hussain, M.M. (2005) Evidence for Multiple Complementary Pathways for Efficient Cholesterol Absorption in Mice. Journal of Lipid Research, 46, 1491-1501. https://doi.org/10.1194/jlr.M500023-JLR200

[51] Brunham, L.R., Kruit, J.K., Iqbal, J., Fievet, C., Timmins, J.M., Pape, T.D., Coburn, B.A., Bissada, N., Staels, B., Groen, A.K., Hussain, M.M., Parks, J.S., Kuipers, F. and Hayden, M.R. (2006) Intestinal ABCA1 Directly Contributes to HDL Biogenesis in Vivo. Journal of Clinical Investigation, 116, 1052-1062. https://doi.org/10.1172/JCI27352

[52] Wegner, C.J., Kim, B. and Lee, J. (2013) Trust Your Gut: Galvanizing Nutritional Interest in Intestinal Cholesterol Metabolism for Protection Against Cardiovascular Diseases. Nutrients, 5, 208-222. https://doi.org/10.3390/nu5010208

[53] Groen, A.K., Bloks, V.W., Bandsma, R.H., Ottenhoff, R., Chimini, G. and Kuipers, F. (2001) Hepatobiliary Cholesterol Transport Is Not Impaired in Abca1-Null Mice Lacking HDL. Journal of Clinical Investigation, 108, 843-850.

https://doi.org/10.1172/JCI200112473

[54] Kruit, J.K., Plosch, T., Havinga, R., Boverhof, R., Groot, P.H., Groen, A.K. and Kuipers, F. (2005) Increased Fecal Neutral Sterol Loss upon Liver X Receptor Activation Is Independent of Biliary Sterol Secretion in Mice. Gastroenterology, 128, 147-156. https://doi.org/10.1053/j.gastro.2004.10.006

[55] Van der Velde, A.E., Vrins, C.L., van den, O.K., Kunne, C., Oude Elferink, R.P., Kuipers, F. and Groen, A.K. (2007) Direct Intestinal Cholesterol Secretion Contributes Significantly to Total Fecal Neutral Sterol Excretion in Mice. Gastroenterology, 133, 967-975. https://doi.org/10.1053/j.gastro.2007.06.019

[56] Mitchell, J.C., Stone, B.G., Logan, G.M. and Duane, W.C. (1991) Role of Cholesterol Synthesis in Regulation of Bile Acid Synthesis and Biliary Cholesterol Secretion in Humans. Journal of Lipid Research, 32, 1143-1149.

[57] Van der Velde, A.E., van Dijk, T.H., Vrins, C.L., van, M.H., Havinga, R., Bijsterveld, K., Tietge, U.J., Groen, A.K. and Kuipers, F. (2009) Activation of the Liver X Receptor Stimulates Trans-Intestinal Excretion of Plasma Cholesterol. Journal of Biological Chemistry, 284, 19211-19219. https://doi.org/10.1074/jbc.M109.014860

[58] Vrins, C.L., van der Velde, A.E., van den, O.K., Levels, J.H., Huet, S., Oude Elferink, R.P., Kuipers, F. and Groen, A.K. (2009) Peroxisome Proliferator-Activated Receptor Delta Activation Leads to Increased Transintestinal Cholesterol Efflux. Journal of Lipid Research, 50, 2046-2054.

https://doi.org/10.1194/jlr.M800579-JLR200

[59] Jakulj, L., Vissers, M.N., van Roomen, C.P., van der Velde, A.E., Vrins, C.L., Kunne, C., Stellaard, F., Kastelein, J.J. and Groen, A. K. (2010) Ezetimibe Stimulates Faecal Neutral Sterol Excretion Depending on ABCG8 Function in Mice. FEBS Letters, 584, 3625-3628. https://doi.org/10.1016/j.febslet.2010.07.035

[60] Sokolovic, M., Sokolovic, A., van Roomen, C.P., Gruber, A., Ottenhoff, R., Scheij, S., Hakvoort, T. B., Lamers, W.H. and Groen, A.K. (2010) Unexpected Effects of Fasting on Murine Lipid Homeostasis-Transcriptomic and Lipid Profiling. Journal of Hepatology, 52, 737-744. https://doi.org/10.1016/j.jhep.2009.11.028

[61] Van, B.A., Werder, M., Thuahnai, S.T., Han, C.H., Duong, P., Williams, D.L., Wettstein, P., Schulthess, G., Phillips, M.C. and Hauser, H. (2005) Class B Scavenger Receptor-Mediated Intestinal Absorption of Dietary Beta-Carotene and Choles- 
terol. Biochemistry, 44, 4517-4525. https://doi.org/10.1021/bi0484320

[62] Nauli, A.M., Nassir, F., Zheng, S., Yang, Q., Lo, C.M., Vonlehmden, S.B., Lee, D., Jandacek, R.J., Abumrad, N.A. and Tso, P. (2006) CD36 Is Important for Chylomicron Formation and Secretion and May Mediate Cholesterol Uptake in the Proximal Intestine. Gastroenterology, 131, 1197-1207.

https://doi.org/10.1053/j.gastro.2006.08.012

[63] Bietrix, F., Yan, D., Nauze, M., Rolland, C., Bertrand-Michel, J., Comera, C., Schaak, S., Barbaras, R., Groen, A.K., Perret, B., Terce, F. and Collet, X. (2006) Accelerated lipid absorption in mice overexpressing intestinal SR-BI. Journal of Biological Chemistry, 281, 7214-7219. https://doi.org/10.1074/jbc.M508868200

[64] Hauser, H., Dyer, J.H., Nandy, A., Vega, M.A., Werder, M., Bieliauskaite, E., Weber, F.E., Compassi, S., Gemperli, A., Boffelli, D., Wehrli, E., Schulthess, G. and Phillips, M.C. (1998) Identification of a Receptor Mediating Absorption of Dietary Cholesterol in the Intestine. Biochemistry, 37, 17843-17850.

https://doi.org/10.1021/bi982404y

[65] Wang, D.Q. and Carey, M.C. (2002) Susceptibility to Murine Cholesterol Gallstone Formation Is Not Affected by Partial Disruption of the HDL Receptor SR-BI. Biochimica et Biophysica Acta, 1583, 141-150. https://doi.org/10.1016/S1388-1981(02)00194-4

[66] Van der Velde, A.E., Kruit, J.K., Havinga, R., Baller, J.F., Chimini, G., Lestavel, S., Staels, B., Groot, P.H., Groen, A.K. and Kuipers, F. (2005) Reduced Cholesterol Absorption upon PPARdelta Activation Coincides with Decreased Intestinal Expression of NPC1L1. Journal of Lipid Research, 46, 526-534. https://doi.org/10.1194/jlr.M400400-JLR200

[67] Valasek, M.A., Clarke, S.L. and Repa, J.J. (2007) Fenofibrate Reduces Intestinal Cholesterol Absorption via PPARalpha-Dependent Modulation of NPC1L1 Expression in Mouse. Journal of Lipid Research, 48, 2725-2735. https://doi.org/10.1194/jlr.M700345-JLR200

[68] Huff, M.W., Pollex, R.L. and Hegele, R.A. (2006) NPC1L1: Evolution from Pharmacological Target to Physiological Sterol Transporter. Arteriosclerosis, Thrombosis, and Vascular Biology, 26, 2433-2438. https://doi.org/10.1161/01.ATV.0000245791.53245.ee

[69] Yu, L., Bharadwaj, S., Brown, J.M., Ma, Y., Du, W., Davis, M.A., Michaely, P., Liu, P., Willingham, M.C. and Rudel, L.L. (2006) Cholesterol-Regulated Translocation of NPC1L1 to the Cell Surface Facilitates Free Cholesterol Uptake. Journal of Biological Chemistry, 281, 6616-6624. https://doi.org/10.1074/jbc.M511123200

[70] Gylling, H. and Miettinen, T.A. (1996) Cholesterol Absorption and Lipoprotein Metabolism in Type II Diabetes Mellitus with and without coronary Artery Disease. Atherosclerosis, 126, 325-332. https://doi.org/10.1016/0021-9150(96)05930-8

[71] Lally, S., Tan, C.Y., Owens, D. and Tomkin, G.H. (2006) Messenger RNA Levels of Genes Involved in Dysregulation of Postprandial Lipoproteins in Type 2 Diabetes: The Role of Niemann-Pick C1-Like 1, ATP-Binding Cassette, Transporters G5 and G8, and of Microsomal Triglyceride Transfer Protein. Diabetologia, 49, 1008-1016. https://doi.org/10.1007/s00125-006-0177-8

[72] Janowski, B.A., Grogan, M.J., Jones, S.A., Wisely, G.B., Kliewer, S.A., Corey, E.J. and Mangelsdorf, D.J. (1999) Structural Requirements of Ligands for the Oxysterol Liver $\mathrm{X}$ Receptors LXRalpha and LXRbeta. Proceedings of the National Academy of Sciences of the United States of America, 96, 266-271. https://doi.org/10.1073/pnas.96.1.266

[73] Calkin, A.C. and Tontonoz, P. (2010) Liver X Receptor Signaling Pathways and 
Atherosclerosis. Arteriosclerosis, Thrombosis, and Vascular Biology, 30, 1513-1518. https://doi.org/10.1161/ATVBAHA.109.191197

[74] Edmondson, A.C., Braund, P.S., Stylianou, I.M., Khera, A.V., Nelson, C.P., Wolfe, M.L., Derohannessian, S.L., Keating, B.J., Qu, L., He, J., Tobin, M.D., Tomaszewski, M., Baumert, J., Klopp, N., Doring, A., Thorand, B., Li, M., Reilly, M.P., Koenig, W., Samani, N.J. and Rader, D.J. (2011) Dense Genotyping of Candidate Gene Loci Identifies Variants Associated with High-Density Lipoprotein Cholesterol. Circulation: Cardiovascular Genetics, 4, 145-155. https://doi.org/10.1161/circgenetics.110.957563

[75] Repa, J.J., Berge, K.E., Pomajzl, C., Richardson, J.A., Hobbs, H. and Mangelsdorf, D.J. (2002) Regulation of ATP-Binding Cassette Sterol Transporters ABCG5 and ABCG8 by the liver X Receptors Alpha and Beta. Journal of Biological Chemistry, 277, 18793-18800. https://doi.org/10.1074/jbc.M109927200

[76] Lee, R.G., Willingham, M.C., Davis, M.A., Skinner, K.A. and Rudel, L.L. (2000) Differential Expression of ACAT1 and ACAT2 among Cells within Liver, Intestine, Kidney, and Adrenal of Nonhuman Primates. Journal of Lipid Research, 41, 1991-2001.

[77] Chang, C.C., Huh, H.Y., Cadigan, K.M. and Chang, T.Y. (1993) Molecular Cloning and Functional Expression of Human Acyl-Coenzyme A: Cholesterol Acyltransferase cDNA in Mutant Chinese Hamster Ovary Cells. Journal of Biological Chemistry, 268, 20747-20755.

[78] Meiner, V., Tam, C., Gunn, M.D., Dong, L.M., Weisgraber, K.H., Novak, S., Myers, H.M., Erickson, S.K. and Farese, R.V. (1997) Tissue Expression Studies on the Mouse Acyl-CoA: Cholesterol Acyltransferase Gene (Acact): Findings Supporting the Existence of Multiple Cholesterol Esterification Enzymes in Mice. Journal of Lipid Research, 38, 1928-1933.

[79] Anderson, R.A., Joyce, C., Davis, M., Reagan, J.W., Clark, M., Shelness, G.S. and Rudel, L.L. (1998) Identification of a form of Acyl-CoA: Cholesterol Acyltransferase Specific to Liver and Intestine in Nonhuman Primates. Journal of Biological Chemistry, 273, 26747-26754. https://doi.org/10.1074/jbc.273.41.26747

[80] Cases, S., Novak, S., Zheng, Y.W., Myers, H.M., Lear, S.R., Sande, E., Welch, C.B., Lusis, A.J., Spencer, T.A., Krause, B.R., Erickson, S.K. and Farese, R.V. (1998) ACAT-2, a Second Mammalian Acyl-CoA: Cholesterol Acyltransferase. Its Cloning, Expression, and Characterization. Journal of Biological Chemistry, 273, 2675526764. https://doi.org/10.1074/jbc.273.41.26755

[81] Buhman, K.K., Accad, M., Novak, S., Choi, R.S., Wong, J.S., Hamilton, R.L., Turley, S. and Farese, R.V. (2000) Resistance to Diet-Induced Hypercholesterolemia and Gallstone Formation in ACAT2-Deficient Mice. Nature Medicine, 6, 1341-1347. https://doi.org/10.1038/82153

[82] Iqbal, J., Rudel, L.L. and Hussain, M.M. (2008) Microsomal Triglyceride Transfer Protein Enhances Cellular Cholesteryl Esterification by Relieving Product Inhibition. Journal of Biological Chemistry, 283, 19967-19980. https://doi.org/10.1074/jbc.M800398200

[83] Hussain, M.M., Fatma, S., Pan, X. and Iqbal, J. (2005) Intestinal Lipoprotein Assembly. Current Opinion in Lipidology, 16, 281-285. https://doi.org/10.1097/01.mol.0000169347.53568.5a

[84] Clark, S.B. and Tercyak, A.M. (1984) Reduced Cholesterol Transmucosal Transport in Rats with Inhibited Mucosal Acyl CoA: Cholesterol Acyltransferase and Normal Pancreatic Function. Journal of Lipid Research, 25, 148-159.

[85] Sittiwet, C., Gylling, H., Hallikainen, M., Pihlajamaki, J., Moilanen, L., Laaksonen, 
D.E., Niskanen, L., Agren, J.J., Laakso, M. and Miettinen, T.A. (2007) Cholesterol Metabolism and Non-Cholesterol Sterol Distribution in Lipoproteins of Type $1 \mathrm{Di}$ abetes: The Effect of Improved Glycemic Control. Atherosclerosis, 194, 465-472. https://doi.org/10.1016/j.atherosclerosis.2006.08.044

[86] Feingold, K.R., Wiley, M.H., MacRae, G., Moser, A.H., Lear, S.R. and Siperstein, M.D. (1982) The Effect of Diabetes Mellitus on Sterol Synthesis in the Intact Rat. Diabetes, 31, 388-395. https://doi.org/10.2337/diab.31.5.388

[87] Feingold, K.R., Lear, S.R. and Moser, A.H. (1984) De Novo Cholesterol Synthesis in Three Different Animal Models of Diabetes. Diabetologia, 26, 234-239. https://doi.org/10.1007/BF00252414

[88] Nakayama, H. and Nakagawa, S. (1977) Influence of Streptozotocin Diabetes on Intestinal 3-Hydroxy-3-Methylglutaryl Coenzyme A Reductase Activity in the Rat. Diabetes, 26, 439-444. https://doi.org/10.2337/diab.26.5.439

[89] Easom, R.A. and Zammit, V.A. (1985) Effects of Diabetes on the Expressed and Total Activities of 3-Hydroxy-3-Methylglutaryl-CoA Reductase in Rat Liver in Vivo. Reversal by Insulin Treatment. Biochemical Journal, 230, 747-752. https://doi.org/10.1042/bj2300747

[90] Miettinen, T.A. and Gylling, H. (2002) Ineffective Decrease of Serum Cholesterol by Simvastatin in a Subgroup of Hypercholesterolemic Coronary Patients. Atherosclerosis, 164, 147-152. https://doi.org/10.1016/S0021-9150(02)00054-0

[91] Hawes, B.E., O’neill, K.A., Yao, X., Crona, J.H., Davis, H.R., Graziano, M.P. and Altmann, S.W. (2007) In Vivo Responsiveness to Ezetimibe Correlates with Niemann-Pick C1 Like-1 (NPC1L1) Binding Affinity: Comparison of Multiple Species NPC1L1 Orthologs. Molecular Pharmacology, 71, 19-29. https://doi.org/10.1124/mol.106.027896

[92] Davis, H.R., Compton, D.S., Hoos, L. and Tetzloff, G. (2001) Ezetimibe, a Potent Cholesterol Absorption Inhibitor, Inhibits the Development of Atherosclerosis in ApoE Knockout Mice. Arteriosclerosis, Thrombosis, and Vascular Biology, 21, 2032-2038. https://doi.org/10.1161/hq1201.100260

[93] Davis, H.R., Hoos, L.M., Tetzloff, G., Maguire, M., Zhu, L.J., Graziano, M.P. and Altmann, S.W. (2007) Deficiency of Niemann-Pick C1 Like 1 Prevents Atherosclerosis in ApoE-/-Mice. Arteriosclerosis, Thrombosis, and Vascular Biology, 27, 841-849. https://doi.org/10.1161/01.ATV.0000257627.40486.46

[94] Sudhop, T., Reber, M., Tribble, D., Sapre, A., Taggart, W., Gibbons, P., Musliner, T., Von, B.K. and Lutjohann, D. (2009) Changes in Cholesterol Absorption and Cholesterol Synthesis Caused by Ezetimibe and/or Simvastatin in Men. Journal of Lipid Research, 50, 2117-2123. https://doi.org/10.1194/jlr.P900004-JLR200

[95] Davis, H.R. and Veltri, E.P. (2007) Zetia: inhibition of Niemann-Pick C1 like 1 (NPC1L1) to Reduce Intestinal Cholesterol Absorption and Treat Hyperlipidemia. Journal of Atherosclerosis and Thrombosis, 14, 99-108. https://doi.org/10.5551/jat.14.99

[96] Gleeson, A., Owens, D., Collins, P., Johnson, A. and Tomkin, G.H. (2000) The Relationship between Cholesterol Absorption and Intestinal Cholesterol Synthesis in the Diabetic Rat Model. International Journal of Experimental Diabetes Research, 1, 203-210. https://doi.org/10.1155/EDR.2000.203

[97] Deushi, M., Nomura, M., Kawakami, A., Haraguchi, M., Ito, M., Okazaki, M., Ishii, H. and Yoshida, M. (2007) Ezetimibe Improves Liver Steatosis and Insulin Resistance in Obese Rat Model of Metabolic Syndrome. FEBS Letters, 581, 5664-5670. https://doi.org/10.1016/j.febslet.2007.11.023

[98] Nomura, M., Ishii, H., Kawakami, A. and Yoshida, M. (2009) Inhibition of Hepatic 
Niemann-Pick C1-Like 1 Improves Hepatic Insulin Resistance. American Journal of Physiology, Endocrinology and Metabolism, 297, E1030-E1038. https://doi.org/10.1152/ajpendo.00343.2009

[99] Labonte, E.D., Camarota, L.M., Rojas, J.C., Jandacek, R.J., Gilham, D.E., Davies, J.P., Ioannou, Y. A., Tso, P., Hui, D.Y. and Howles, P.N. (2008) Reduced Absorption of Saturated Fatty Acids and Resistance to Diet-Induced Obesity and Diabetes by Ezetimibe-Treated and Npc1l1-/-Mice. American Journal of Physiology, Gastrointestinal and Liver Physiology, 295, G776-G783.

https://doi.org/10.1152/ajpgi.90275.2008

[100] Bloks, V.W., Bakker-Van Waarde, W.M., Verkade, H.J., Kema, I.P., Wolters, H., Vink, E., Groen, A. K. and Kuipers, F. (2004) Down-Regulation of Hepatic and Intestinal ABCG5 and ABCG8 Expression Associated with Altered Sterol Fluxes in Rats with Streptozotocin-Induced Diabetes. Diabetologia, 47, 104-112. https://doi.org/10.1007/s00125-003-1261-y

[101] Lally, S., Owens, D. and Tomkin, G.H. (2007) The Different Effect of Pioglitazone as Compared to Insulin on Expression of Hepatic and Intestinal Genes Regulating Post-Prandial Lipoproteins in Diabetes. Atherosclerosis, 193, 343-351. https://doi.org/10.1016/j.atherosclerosis.2006.09.031

[102] Guardamagna, O., Abello, F., Baracco, V., Federici, G., Bertucci, P., Mozzi, A., Mannucci, L., Gnasso, A. and Cortese, C. (2011) Primary Hyperlipidemias in Children: Effect of Plant Sterol Supplementation on Plasma Lipids and Markers of Cholesterol Synthesis and Absorption. Acta Diabetologica, 48, 127-133. https://doi.org/10.1007/s00592-010-0233-1

[103] John, S., Sorokin, A.V. and Thompson, P.D. (2007) Phytosterols and Vascular Disease. Current Opinion in Lipidology, 18, 35-40. https://doi.org/10.1097/MOL.0b013e328011e9e3

[104] Thompson, G.R. and Grundy, S.M. (2005) History and Development of Plant Sterol and Stanol Esters for Cholesterol-Lowering Purposes. American Journal of Cardiology, 96, 3D-9D. https://doi.org/10.1016/j.amjcard.2005.03.013

[105] Weingartner, O., Lutjohann, D., Ji, S., Weisshoff, N., List, F., Sudhop, T., Von, B.K., Gertz, K., Konig, J., Schafers, H.J., Endres, M., Bohm, M. and Laufs, U. (2008) Vascular Effects of Diet Supplementation with Plant Sterols. Journal of the American College of Cardiology, 51, 1553-1561. https://doi.org/10.1016/j.jacc.2007.09.074

[106] Helske, S., Miettinen, T., Gylling, H., Mayranpaa, M., Lommi, J., Turto, H., Werkkala, K., Kupari, M. and Kovanen, P.T. (2008) Accumulation of Cholesterol Precursors and Plant Sterols in Human Stenotic Aortic Valves. Journal of Lipid Research, 49, 1511-1518. https://doi.org/10.1194/jlr.M800058-JLR200 
Submit or recommend next manuscript to SCIRP and we will provide best service for you:

Accepting pre-submission inquiries through Email, Facebook, LinkedIn, Twitter, etc. A wide selection of journals (inclusive of 9 subjects, more than 200 journals)

Providing 24-hour high-quality service

User-friendly online submission system

Fair and swift peer-review system

Efficient typesetting and proofreading procedure

Display of the result of downloads and visits, as well as the number of cited articles Maximum dissemination of your research work

Submit your manuscript at: http://papersubmission.scirp.org/

Or contact abc@scirp.org 